\title{
Experimental investigation and thermodynamic study of heavy metal removal from industrial wastewater using pomegranate peel
}

\author{
Thamer Mohammed ${ }^{1}$, Raheek Ibrahim $^{2,}{ }^{*}$, and Alia Naji ${ }^{1}$ \\ ${ }^{1}$ Chemical Engineering Department, University of Technology, Baghdad, Iraq \\ ${ }^{2}$ Electromechanical Engineering Department, University of Technology, Baghdad, Iraq
}

\begin{abstract}
The objective of the study is to treat industrial wastewater and perform a thermodynamic experimental study for more economical and efficient adsorption process. This has been done by biosorption and chemisorption of chromium ions from synthetic wastewater into already prepared pomegranate peel as a natural adsorbent. Pomegranate peel proved to be an economic solution since it is available locally and it has an elevated adsorption capacity. Adsorption has been done in a fixed bed column $(10 \mathrm{~cm}$ inside diameter, and $30 \mathrm{~cm}$ height) with continuous flow rate of $1 \mathrm{ml} / \mathrm{min}$. The characteristic properties of adsorption for the pomegranate peel, analyzed by FTIR and SEM, proved that pomegranate peel is a good adsorbent because of its effective combinations and holes on its exterior. Also, comparing between adsorption ability of pomegranate peel together with Langmuir and Freundlich models indicates that Langmuir is preferable in fitting the experimental data. However, the elimination efficiency of the pomegranate peel was $90 \%$, and the greatest adsorption capability was $9.45 \mathrm{mg} / \mathrm{g}$. While, thermodynamic study results showed that endothermic adsorption was approved from positive values of $\Delta \mathrm{H}^{\circ}$, also the negative values of $\Delta \mathrm{G}^{\circ}$ proved that the adsorption is unprompted and convenient.
\end{abstract}

\section{Introduction}

Water pollution with poisonous heavy metals by industrial wastewater discharge is an environmental problem through the world [1]. Fast manufacturing and growth sent out heavy metals into the water. Industries like mining, metal plating and battery manufacturing result into a release of heavy metals into aquatic ecosystem [2,3]. Biosorption is an environment friendly process for metal removal since it can be considered as cost effective and efficient adsorbents for heavy metal removal. Many biomasses can be used as biosorbent like waste agriculture materials, and different processes have been utilized in the treatment, this includes biological method through biosorption. Biosorption advantages are: low cost, high efficiency and availability during most of the year [4]. Local fruit wastes are successfully applied for the treatment of wastewater polluted with heavy metals, but it needs a further understanding of biosorption mechanism [5]. Pomegranate is a common fruit; it includes an edible part, seed, and peel. The pomegranate peel (PP) forms 5
$\%$ to $15 \%$ of its total weight [6]. Laterally, several researches were achieved for employing a pomegranate peel to eliminate $\mathrm{Cr}(\mathrm{VI}), \mathrm{Ni}(\mathrm{II}), \mathrm{Pb}(\mathrm{II})$, and $\mathrm{Cu}(\mathrm{II})$ from water samples [7, and 8]. Thermodynamic study was performed using adsorption measurements [9]. The aim of the present work is to remove chromium ions from synthetic wastewater using pomegranate peels as a natural biomass with an efficient, low cost, and environmental friendly adsorption process. In addition to performing a thermodynamic study to explain the impact of temperature on feasibility of the adsorption process, the characterization of PP with FTIR and SEM are done to present the impact of chromium ion binding with the functional combinations in the exterior surface of PP as natural adsorbent. Also, the adsorption isotherms study is performed.

\section{Materials and method}

\subsection{Adsorbent preparation}

\footnotetext{
${ }^{*}$ Corresponding author: doctorraheek@yahoo.com
} 
The pomegranate peels bought locally from a marketing center, washing it using tap water and distilled water. After that peels were cut off to small portions then dried by sun light for three days. The dried portions were dried again using an oven at $80^{\circ} \mathrm{C}$ for $36 \mathrm{hrs}$. The dried materials were grinded and sieved to give $1 \mathrm{~mm}$ particle size.

\section{$2.2 \mathrm{Cr}(\mathrm{VI})$ solution preparation}

Cr (VI) solution was prepared by dissolving the nitrates salts in deionized water and diluted to a desired metal concentration.

\subsection{Analysis method}

Atomic absorption instrument type (AA250, China) used to find $\mathrm{Cr}(\mathrm{VI})$ concentration.

\subsection{Thermodynamic experiments}

Thermodynamic experiments were done using $25 \mathrm{ml}$ of chromium solution of $10 \mathrm{mg} / \mathrm{L}$ concentration, $\mathrm{PP}$ dose of $0.01 \mathrm{~g} / 25 \mathrm{ml}$ at different temperatures $\left(30,40,50{ }^{\circ} \mathrm{C}\right)$ for contact time of $(1 \mathrm{hr})$. The amount of $\mathrm{Cr}(\mathrm{VI})$ adsorbed per unit of pomegranate peel (PP) and removal percentages were calculated according to mass balance of chromium concentration as:

$q_{e}=\frac{\left(C_{i}-C_{f}\right) V}{m}$

$\%$ Re moval $=\frac{C_{i}-C_{f}}{C_{i}} \times 100$

\subsection{Column tests}

In this experiment $25 \mathrm{gm}$ of PP powder were placed in $30 \mathrm{~cm}$ high, $10 \mathrm{~cm}$ i.d. glass column as shown in Fig. 1. After that $100 \mathrm{ml}$ of the heavy metal solution were inserted into the column. The out flowing samples of $5.0 \mathrm{ml}$ were assembled, labeled and analyzed. The samples were filtered using filter paper No. 40 and the quantity of chromium ions was found by atomic absorption.

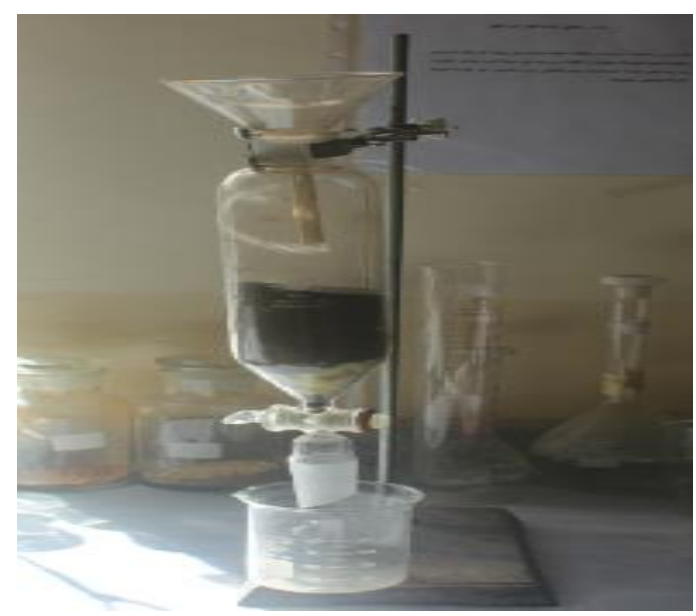

Fig. 1. Experimental apparatus used in the experiments.

\section{Results and discussion}

\subsection{SEM test of pomegranate peel}

The porous composition of $(50 \mu \mathrm{m})$ particle size of pomegranate peel was noticed with $500 \mathrm{X}$ resolution (Figs. 2, and 3). The test display several holes in the surface that are able to uptake chromium ions. The test result showed that there is a noticeable variation in surface structure of PP before and after $\mathrm{Cr}(\mathrm{VI})$ adsorption.

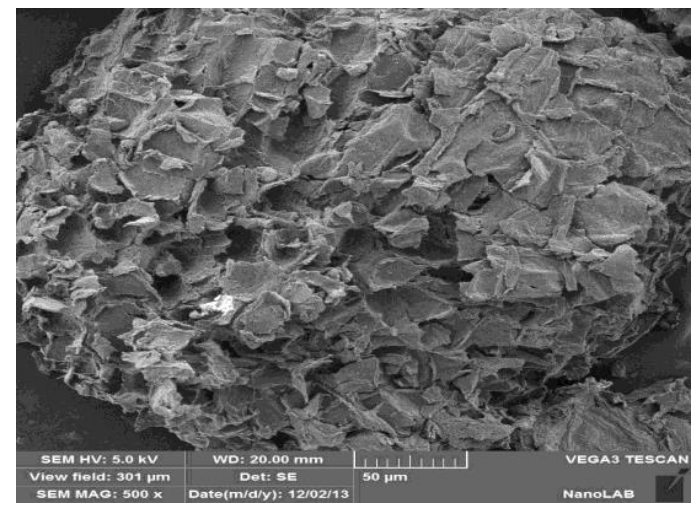

Fig. 2, SEM image of pomegranate peel before adsorption.

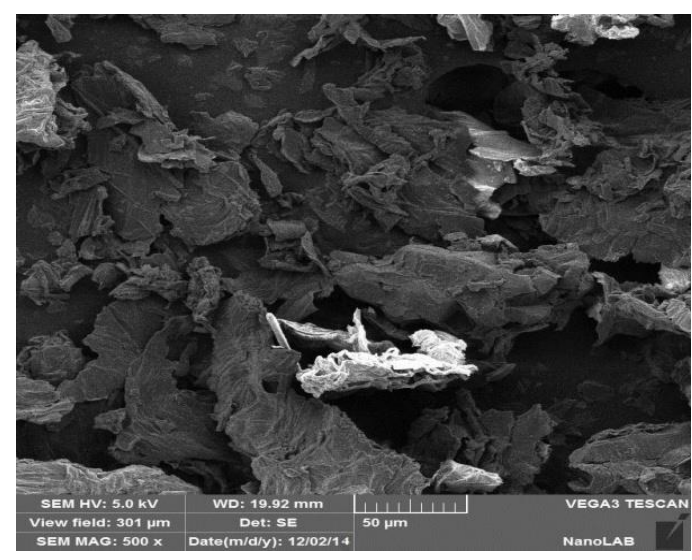

Fig. 3, SEM image of pomegranate peel after adsorption.

\subsection{FTIR characterization of pomegranate peel}

The FTIR analysis of PP before and after $\mathrm{Cr}$ (VI) binding is offered by Figure 4. FTIR analysis was utilized to show the variation in the functional groups before and after adsorption. The test demonstrates several peaks, the peak at 2360.67 and $2341.7 \mathrm{~cm}^{-1}$ has been seen which could be as a result of chromium ion binding and adsorbing in the surface of the pomegranate peel. 


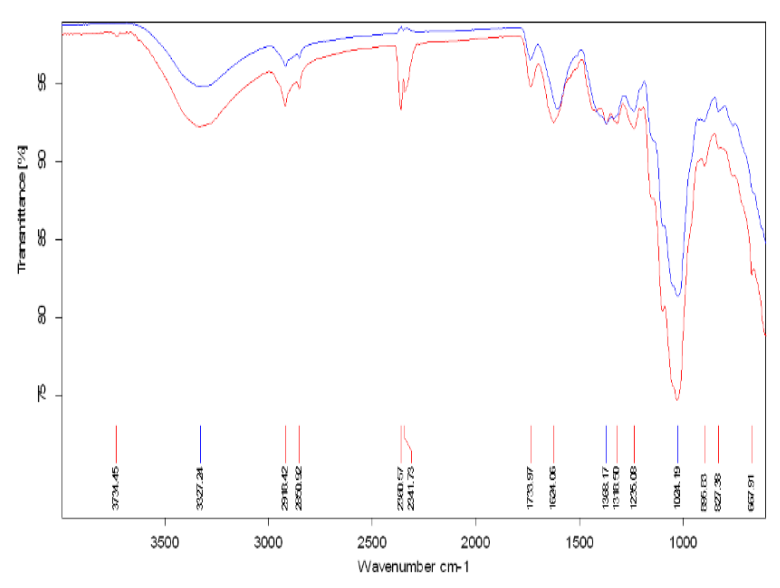

Fig.4, FTIR analysis of pomegranate peel before and after adsorption (blue color is PP before adsorption, and red color is PP after adsorption).

\subsection{Thermodynamic analysis}

The thermodynamic properties like change in free energy $\Delta \mathrm{G}^{\circ}$, enthalpy $\Delta \mathrm{H}^{\circ}$, and entropy $\Delta \mathrm{S}^{\circ}$ have been obtained using:

$$
\begin{gathered}
K_{C}=\frac{C_{A C}}{C_{e}} \quad \ldots \ldots \ldots \ldots \ldots \\
\Delta G^{\mathrm{O}}=-R T \ln K_{C} \\
\log K_{C}=\frac{\Delta S^{0}}{2.303 R}-\frac{\Delta H^{0}}{2.303 R T}
\end{gathered}
$$

Vant Hoff equation (No.5) was utilized to evaluate $\Delta \mathrm{H}^{\circ}$ and $\Delta S^{\circ}$. From the intercept and slope for $\log \mathrm{K}_{\mathrm{c}}$ Vs. $1 / \mathrm{T}$ as shown in Fig.5, the results are available in Table 1.

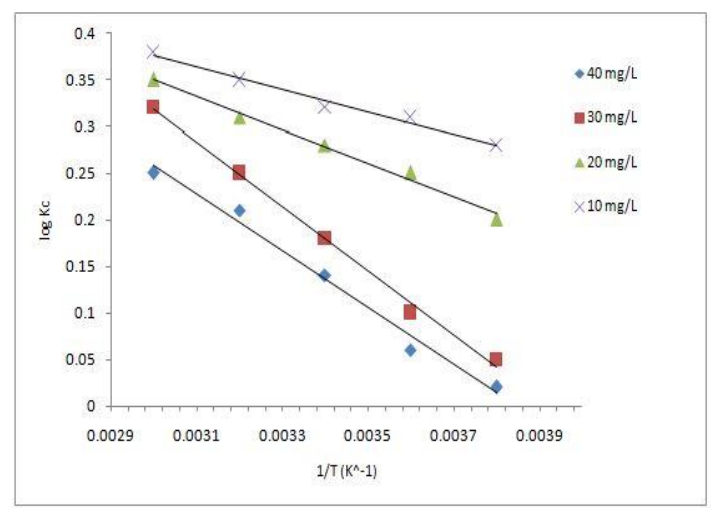

Fig. 5, Aplot of Vant Hoff equation for $\mathrm{Cr}(\mathrm{VI})$ adsorption onto $\mathrm{PP}$ at different $\mathrm{Cr}(\mathrm{VI})$ concentrations.

The values of $\Delta \mathrm{H}^{\circ}$ lie between 4.65 to $15.26 \mathrm{kJmol}^{-1}$ which proved the biosorption, the results indicate that biosorption is most effective. The positive values of $\Delta \mathrm{H}^{\circ}$ indicate the endothermic type of adsorption and it decides the potential of physical adsorption. Since in the adsorption process the rising of system temperature tends to enhance adsorption of $\mathrm{Cr}$ (VI), these principles are different from chemisorption. $\Delta \mathrm{G}^{\circ}$ values are gained from Eq. 4, the negative values of $\Delta \mathrm{G}^{\circ}$ shown in Table 1 , suggest it is highly appropriate and unprompted. Furthermore, it was noticed that negative values of $\Delta G^{\circ}$ increased as the system temperature was increased, which indicates that the adsorption is more superior at high temperatures. The positive values of $\Delta \mathrm{S}^{\circ}$ are shown in Table 1, proved the rising in disturbance at the interface of chromium ion with PP.

Table 1. Thermodynamic properties of $\mathrm{Cr}(\mathrm{II})$ adsorption on Pomegranate Peels.

\begin{tabular}{|l|l|l|l|l|l|l|l|}
\hline $\begin{array}{l}\text { Cr(VI) } \\
\text { conc. }\end{array}$ & $\Delta \mathrm{H}^{\circ}$ & $\Delta \mathrm{S}^{\circ}$ & \multicolumn{5}{|c|}{$\begin{array}{l}\Delta \mathrm{G}^{\circ} \\
\mathbf{k J} / \mathbf{m o l}\end{array}$} \\
\hline $\mathrm{mg} / \mathrm{l}$ & $\mathrm{kJ} / \mathrm{mol}$ & $\mathrm{J} / \mathrm{mol}$ & $20^{\circ} \mathrm{C}$ & $30^{\circ} \mathrm{C}$ & $40^{\circ} \mathrm{C}$ & $50^{\circ} \mathrm{C}$ & $\mathrm{R}^{2}$ \\
\hline 10 & 4.65 & 18.86 & -1.56 & -1.73 & -1.85 & -2.11 & 0.998 \\
\hline 20 & 7.32 & 26.38 & -1.34 & -1.43 & -1.75 & -1.93 & 0.978 \\
\hline 30 & 14.42 & 48.53 & -0.83 & -0.99 & -1.55 & -2.21 & 0.954 \\
\hline 40 & 15.26 & 49.49 & -0.06 & -0.68 & -1.31 & -1.43 & 0.943 \\
\hline
\end{tabular}

\subsection{Adsorption isotherms for the adsorption of $\mathrm{Cr}(\mathrm{VI})$ onto $\mathrm{PP}$}

The adsorption results were tested using Freundlich and Langmuir models at different temperatures. The parameters of each adsorption isotherm were obtained. The linear form of Langmuir isotherm is given by Eq. 6 [11]:

$$
1 / q_{e}=\left(1 / q_{m}\right) \times(1 / b) \times\left(1 / C_{e}\right)+\left(1 / q_{m}\right)
$$

It was demonstrated that the plot of $1 / q_{e}$ versus $1 / C_{e}$ displays a straight line (Fig.6), and the values of $b$ and $q_{m}$ are documented in Table 2. Also, the values of $q_{e}$ estimated from the model as $q_{e}(c a l$.$) is quite$ around the experimental values as $q_{e}$ (exp.). Thus, the Langmuir isotherm fits well the experimental data. The linear form of Freundlich isotherm is given by Eq. 7 [11].

$$
\log q_{e}=\log K+(1 / n) \log C_{e}
$$

It is observed that the $\log q_{e}$ versus $\log C_{e}$ gives a straight line relation as shown in Fig.7. The values of Freundlich constants are given in Table 2, the Freundlich isotherm is also complied because $q_{e}$ (exp.) values are near $q_{e}(c a l$.$) . In addition to that, the high$ correlation coefficient $\left(R^{2}\right)$ for $\mathrm{Cr}(\mathrm{VI})$ adsorption by PP refers that the system undergoes both Langmuir and Freundlich models, with better fitted to Langmuir model. 
Table 2 shows that $n$ value of $\mathrm{Cr}(\mathrm{VI})$ is greater than 1 ; it is proved that adsorption is convenient for removal of $\mathrm{Cr}$ (VI) by pomegranate peel.

Table 2, Isotherms for $\mathrm{Cr}$ (II) removal by pomegranate peels.

\begin{tabular}{|c|c|c|c|c|c|}
\hline \multicolumn{2}{|c|}{ Langmuir coefficients } & \multicolumn{3}{c|}{ Freundlich coefficients } \\
\hline $\begin{array}{c}\text { gmax. } \\
(\mathrm{mg} / \mathrm{g})\end{array}$ & $\begin{array}{c}\mathrm{b} \\
(\mathrm{l} / \mathrm{mg})\end{array}$ & $\mathrm{R}^{2}$ & $\begin{array}{c}\mathrm{K} \\
(\mathrm{mg} / \mathrm{g})\end{array}$ & $\mathrm{n}$ & $\mathrm{R}^{2}$ \\
\hline 9.45 & 0.2 & 0.970 & 3.15 & 1.2 & 0.953 \\
\hline
\end{tabular}

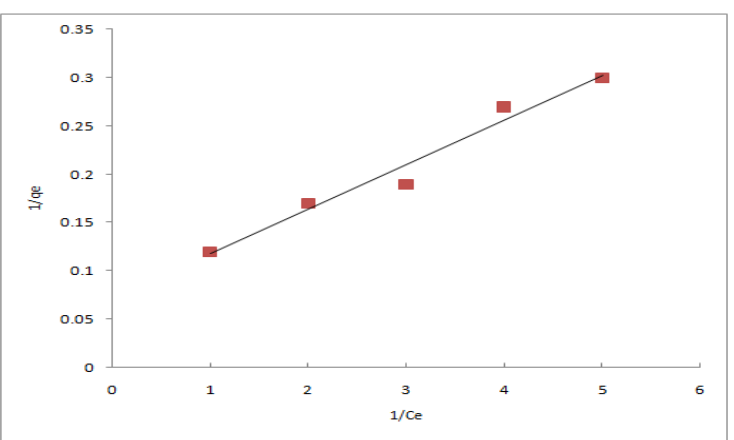

Fig. 6, Langmuir Isotherm for adsorption of $\mathrm{Cr}(\mathrm{VI})$ on PP.

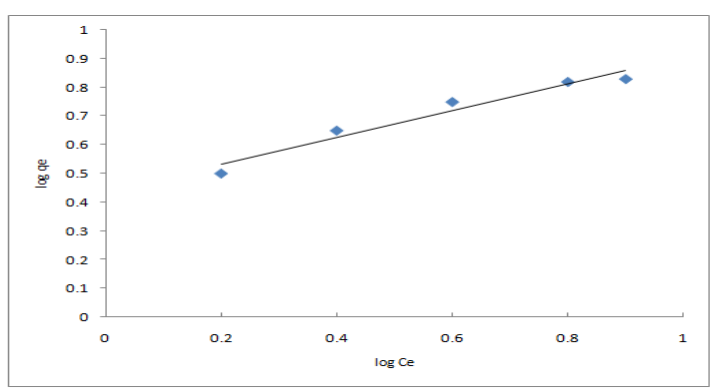

Fig. 7, Freundlich Isotherm for adsorption of $\mathrm{Cr}(\mathrm{VI})$ on PP.

\section{Conclusions}

From the experimental results of this work, it can be concluded that pomegranate peel proved to be an efficient and economical natural adsorbent for remediation of $\mathrm{Cr}(\mathrm{VI})$ ions from industrial wastewater. The elimination efficiency of the pomegranate peel was $90 \%$, and the highest possible adsorption capability was $9.45 \mathrm{mg} / \mathrm{g}$. The FTIR and SEM analyses proved that pomegranate peel is a strong adsorbent because of complex structure and holes on its surface. Although, the adsorption capacity of pomegranate peel in comparison with Langmuir and Freundlich models refers that Langmuir is well fitted with the experimental data. Also, thermodynamic investigation demonstrates an endothermic adsorption as well as the process is unprompted and convenient.

\section{List of symbols}

\begin{tabular}{|l|l|}
\hline Symbol & Definition (unit) \\
\hline $\mathrm{b}$ & Constant $(-)$ \\
\hline $\mathrm{C}_{\mathrm{AC}}$ & Concentration of metal ion in the adsorbent $(\mathrm{mg} / \mathrm{L})$ \\
\hline$C_{e}$ & Equilibrium concentration of metal ion $(\mathrm{mg} /)$ \\
\hline $\mathrm{C}_{\mathrm{j}}$ & Initial concentration $(\mathrm{mg} / \mathrm{L})$ \\
\hline $\mathrm{C}_{f}$ & Final concentration $(\mathrm{mg} / \mathrm{L})$ \\
\hline$\Delta \mathrm{G}^{\circ}$ & Change in Gibbs free energy $(\mathrm{kJ} / \mathrm{mol})$ \\
\hline$\Delta \mathrm{H}^{\circ}$ & Change in enthalpy $(\mathrm{kJ} / \mathrm{mol})$ \\
\hline $\mathrm{K}$ & Freundlich constant $(-)$ \\
\hline $\mathrm{K}_{\mathrm{C}}$ & Equilibrium constant $(-)$ \\
\hline $\mathrm{m}$ & Mass of adsorbent $(\mathrm{gm})$ \\
\hline $\mathrm{n}$ & Freundlich constant $(-)$ \\
\hline$q_{e}$ & Amount of adsorbed metal per unit weight $(\mathrm{mg} / \mathrm{g})$ \\
\hline$q_{m}$ & Maximum adsorption capacity $(\mathrm{mg} / \mathrm{g})$ \\
\hline $\mathrm{R}$ & Gas constant $(\mathrm{Kj} / \mathrm{mol} \mathrm{K})$ \\
\hline$\Delta \mathrm{S}^{\circ}$ & Change in entropy $(\mathrm{J} / \mathrm{mol})$ \\
\hline $\mathrm{T}$ & Temperature $(\mathrm{K})$ \\
\hline $\mathrm{V}$ & Volume of solution $(\mathrm{mL})$ \\
\hline
\end{tabular}

\section{References}

1. N. Othman, S. Mohd-Asharuddin and Azizul-Rahman M-F-H. (2013).An Overview of fruit waste as sustainable adsorbent for heavy metal removal.

2. Masoudrohanimoghadam,NavidNasirizadeh, ZienabDashti and EsmeilBabanezhad. Removal of $\mathrm{Fe}(\mathrm{II})$ from aqueous solution using pomegranate peel carbon : equilibrium and kinetic studies.International journal of industrial chemistry (IJIC)a springeropen journal $2013.4: 19$.

3.E.S.Z.ELAshtoukhy.,N.K.Amin, andO.Abdelwahab.(2 008).Removal of lead (II)and copper(II)from aqeuous solution using pomegranate peel as new adsorbant .Desalination.223,162-173.

4. T.V ,Ramachandra, N Ahalya., and R.D Kanamadi.(2008).Biosorption:Techniques and mechanisms .CES Technical Report 110.

5. K.Vijayaraghavan. and Y-S Yun.(2008).Bacterial biosorbent and biosorption.Biotechnology Advances.26,266-291.

6. H.K.Alluri.,S.R. Ronda.,S.SVigaya.,S.B Bondili.,V. Suryanarayana. And P Venkateshwar.(2007) Biosorption: An eco-friendly altervative for heavy metal removal .African journal of Biotechnology Vol.6(25) ,2924-2931.

7. EikaniMH,GolmohammadF,Homami SS (2012) Extraction of pomegranate (punicagranatuml) seed oil using superheated hexane .Food Biprod process 91:3236.

8. EL Nemr A (2009) Potential of pomegranate peel carbon for $\mathrm{Cr}(\mathrm{VI})$ removal from wastewater ,kinetic and isotherm studies ,J Hazard Mater 161:132-141.

9. Chandra Sekhra K, Kamala CT,Chary NSN ,Anjaneyulu Y (2003) Removal of heavy metals using a plant biomass with reference environmental control .Int J Miner Process 68:37-45.

10. Babel S ,kurniawan CT, Chary NSN, Anjaneyulu Y (2003) Removal of heavy

Metals uptake from contaminatedwater: a review .J Hazard Mater 97:219-243.

11. Thamer J. Mohammed, and Raheek I. Ibrahim (2016), Remediation of $\mathrm{Cu}$ (II) from well water of Iraq using cortex of fruit and agriculture waste. Arabian J. for Sci. and Eng., 41:345-355. 